\title{
Antikanser İlaç Etken Madde Busulfana Seçici Katı-Hal PVC Membran Potansiyometrik Mikrosensör
}

\author{
Murat YOLCU*iD, Berna AYDIN ARSLAN \\ Giresun Üniversitesi, Fen Edebiyat Fakültesi, Kimya Bölümü, Giresun \\ Geliş / Received: 13/12/2019, Kabul / Accepted: 08/03/2019
}

\begin{abstract}
Öz
$\mathrm{Bu}$ çalışmada antikanser ilaç etken madde olan busulfan (BUS) için seçici yeni tip katı-hal PVC membran mikrosensör geliştirildi. Bu amaçla busulfan ile tetrafenilboratın iyon çifti sentezlendi ve sensör membran yapısı içerisinde iyonofor madde olarak kullanıldı. Farklı membran bileşimlere sahip busulfan-seçici sensörler üretildi ve sensörlerin potansiyometrik performans özellikleri durgun ortam ölçümleri ile araştırıldı. En iyi potansiyometrik performansı \% 66 nitrofeniloktileter, \% 30 polivinilklorür ve \% 4 iyon-çifti bileşimine sahip sensörün sergilediği belirlendi. Geniş bir doğrusal çalışma aralığında $\left(\sim 2,5 \times 10^{-5}-1,0 \times 10^{-2} \mathrm{M}\right)$; sensörün eğim değerinin $53,3 \pm 3,4 \mathrm{mV}\left(\mathrm{R}^{2}=0,990\right)$, tayin limitinin $1,8 \times 10^{-5} \mathrm{M}$, cevap zamanının $\sim 25 \mathrm{~s}$ ve kullanım ömrünün $\sim 6$ hafta olduğu belirlendi. Geliştirilen busulfan-seçici sensör yardımıyla, kanser tedavisinde kullanılan farmasötik bir ilaç numunesinde busulfan tayini başarıyla gerçekleştirildi. Elde edilen sonuçların \% 95 güven seviyesinde UV metodu ile elde edilen sonuçlarla uyum içerisinde olduğu görüldü.
\end{abstract}

Anahtar Kelimeler: Antikanser, Busulfan, Farmasötik, Potansiyometri, İyon Seçici Sensör

\section{Selective Solid-State PVC-Membrane Potentiometric Microsensor for Anticancer Drug Busulfan}

\begin{abstract}
In this study, a novel solid-state PVC membrane selective microsensor was developed for busulfan which is an anticancer drug active substance. For this purpose ion-pair was synthesized with busulfan and tetraphenylborate, and that ion-pair was used as an ionophore in the structure of sensor membrane. Busulfanselective sensors at different membrane compositions were prepared and their potentiometric performances were investigated under static conditions. It was determined that the sensor membrane at the ratio of $66 \%$ nitrophenyloctylether, $30 \%$ polyvinyl chloride and $4 \%$ ion-pair performed the best potentiometric performances. In a wide concentration range $\left(\sim 2.5 \times 10^{-5}-1.0 \times 10^{-2} \mathrm{M}\right)$; the slope, detection limit, response time and life-time of sensor were determined as $53.3 \pm 3.4 \mathrm{mV}\left(\mathrm{R}^{2}=0.990\right), 1.8 \times 10^{-5} \mathrm{M}, \sim 25 \mathrm{~s}$ and $\sim 6$ weeks, respectively. The prepared busulfan-selective sensor was successfully utilized for the determination of busulfan in pharmaceutical drug sample which is used in the treatment of cancer. It was observed that the obtained results were in agreement with the results obtained by the UV method at $95 \%$ confidence level.
\end{abstract}

Keywords: Anticancer, Busulfan, Pharmaceutical, Potentiometry, Ion Selective Sensor

\section{Giriș}

Günümüzün en yaygın ve ölümcül hastalıkları arasındaki yerini ve önemini koruyan kanser hastalı̆̆ ilgili araştırmalar tüm hızıyla devam etmektedir. Kanser hastalığının tedavisinde genel olarak cerrahi, immünoterapi, kemoterapi ve radyoterapi yöntemlerine başvurulur. İlaç destekli tedavi olarak bilinen kemoterapi yöntemi günümüzde oldukça yaygındır (Eren vd., 2012). Doğal ilaçlarla hazırlanmış tedavi yöntemi olan fitoterapi ise genellikle bitkilerin tamamı veya bazı bölümleri kullanılarak gerçekleştirilir. Fitoterapi yöntemi kullanılarak bazı kanser türlerinin tedavisine yönelik yapılan başarılı bilimsel çalışmalara da son yıllarda rastlamak mümkündür (Gezmen-Karadağ vd., 2013). Kanser tedavisinde kullanılan ilaçlar antikanser (sitotoksik) ilaçlar olarak tanımlanmakta, etki mekanizmaları ve kullanıldıkları kanser türlerine göre DNA- 
etkileşimli ajanlar, antimetabolitler, antitubulin ajanlar, hormonlar, moleküler hedef ajanlar ve antibadiler gibi ana sinıflara ayrilmaktadırlar. Antikanser ilaçlar ile ilgili özellikle sentez ve analiz çalışmalarına sıkça rastlanmaktadır (Nussbaumer vd., 2011).

Kronik miyelojen lösemi tedavisinde kullanılan antikanser ilaç etken madde olan busulfan (BUS); DNA etkileşimli ajan sınıfından alkil ajan grubu içerisinde yer alan bir neoplastik ilaçtır (Şekil 1). Busulfan etken maddesini içeren biyolojik ve farmasötik numuneler için genellikle yüksek basınç sıvı kromatografisi (Kotinkaduwe vd., 1999), siv1 kromatografi-floresans (Peris vd., 1999, Jenke vd., 2004), siv1 kromatografi-kütle spektrometrisi (Mürdter vd., 2001), gaz kromatografisi-kütle spektroskopisi (Abdel-Rehim vd., 2003) ve siv1 kromatografi-ultra viyole spektroskopisi (Quernin vd., 1999), gaz kromatografisielektron yakalama dedektörü (Burns vd., 1995) gibi teknikleri kullanılarak yapılan analiz çalışmalarına rastlamak mümkündür.

Çoğu ilaç analizleri yüksek maliyetli enstrümanlar aracılığıyla uygulanan metotlarla gerçekleştirilmektedir. Daha ekonomik, hızlı, duyarlı, seçici ve basit metotlarla ilaç etken maddelerin tayini önem arz etmektedir. İyon seçici elektrotlar (ISE)'ın tasarımı ve uygulamaları ile ilgili çalışmalara ilgi devam etmektedir. Basit ve ekonomik tasarım, geniş çalışma aralığı, kısa analiz süresi, yüksek seçicilik, doğruluk ve kesinlik, düşük tayin sınırı, ölçüm numunesini kirletmeme ve bulanık çözeltilerde ölçüme izin verme gibi avantajlı özellikleri nedeniyle; ISE'lar pahalı tayin yöntemlerine alternatif olarak kabul görmektedir (Tang vd., 2018). İlaç etken madde tayinleri için potansiyometrik sensörler (Singhal, 2011; Shawish vd., 2015; Ma'mun vd., 2018; Ensafi ve Allafchian, 2011) son yıllarda yaygın olarak kullanılmaktadır.
$\mathrm{Bu}$ çalışmada, busulfan (BUS)'ın tetrafenilborat (TFB) ile iyon çiftinin sentezlenerek iyonofor madde olarak kullanımı ile yeni tip bütünüyle kat1-hal PVC-membran BUS-seçici mikrosensör geliştirilmesi, potansiyometrik performans özelliklerinin araştırılması ve analitik uygulamalarda test edilmesi amaçlandı.

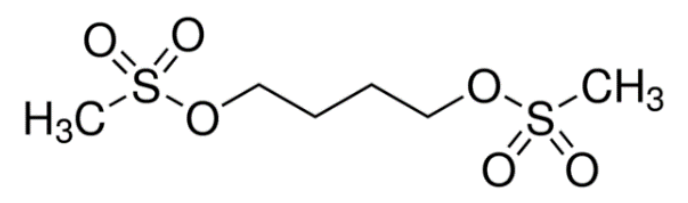

Şekil 1. Busulfan (1,4-bütandiol dimetansülfonat)'ın kimyasal yapısı.

\section{Materyal ve Metot}

\subsection{Kimyasallar}

Busulfan (BUS), tetrahidrofuran (THF), aseton, yüksek molekül ağırlıklı polivinilklorür (PVC), o-nitrofeniloktileter (o-NFOE), dioktilsebekat (DOS), sodyumtetrafenilborat (NaTFB) ve grafit, SigmaAldrich (Bucks, Switzerland) firmasından, epoksi reçinesi (Ultrapur SU 2227 Victor (Italy) firmasindan, sertleştirici (Desmodur RFE ) Bayer AG (Germany) firmasından, çalışmada kullanılan diğer tuzlar ve çözücüler Merck (Darmstadt, Germany) firmasindan sağlandi.

\subsection{Cihazlar}

Potansiyel ölçümleri, tasarımı ve yazılımı araştırma laboratuvarımızda geliştirilen ve bilgisayar programı ile desteklenmiş çok kanall 1 potansiyometre cihaziyla gerçekleştirildi. Potansiyel ölçümlerinde referans elektrot olarak, $\mathrm{Ag} / \mathrm{AgCl}$ elektrot (Basi-MF-2079-RE-5B) kullanıldı. Tartım işlemlerinde, Shimadzu (Model AUX220) analitik terazi kullanıldı. Çözeltilerin hazırlanmasında kullanılan deiyonize su Sartorius Stedim (Arium*611UV) marka deiyonize su (18,6 M 2 ) cihazı kullanılarak temin edildi. UV-Spektroskopi ölçümlerinde Thermo Scientific Evuluation Array model UV-Vis Spektrofotometre 
cihazı kullanıldı. Elementel analiz ölçümleri için Costech ECS 4010 model elementel analiz cihazı kullanıldı. Standart BUS çözeltileri aseton/su çözücü karışımı içerisinde çözülerek hazırlandı ve pH:7,05 fosfat tamponu kullanılarak istenilen derişimlere seyreltildi. Diğer standart çözeltiler deiyonize su ile analitik saflıktaki stoktan hazırlandı ve istenilen derişimlere seyreltildi.

\subsection{Busulfan-tetrafenilborat (BUS-TFB) Iyon Çifti Sentezi}

$10^{-2} \mathrm{M} \mathrm{HCl}$ ve BUS içeren ve sürekli olarak karıştırılan çözeltinin $25 \mathrm{~mL}$ 'sinin üzerine $10^{-2} \mathrm{M}$ sodyum tetrafenilborat çözeltisinin $25 \mathrm{~mL}$ 'si yavaş yavaş ilave edildi. Oluşan beyaz renkteki çökelek (BUS-TFB) süzüldü ve birkaç kez deiyonize suyla y1kandiktan sonra oda koşullarında karanlıkta kurumaya bırakıldı. Kurutulan BUS-TFB bileşiği elektrot üretiminde membran karışımı içerisine alınarak kullanıldı (Çoldur vd., 2015).

\subsection{BUS-Seçici Sensörün Hazırlanması ve Çalışma Yöntemi}

Genel olarak sensörlerin hazırlanması iki aşamadan oluşmuştur (Isildak vd., 2004). Katı kontak karışımının hazırlanması aşamasında; ağırlıça \% 50 grafit, \% 35 Ultrapur SU 2227 ve \% 15 Desmadur RFE içeren karışım THF çözücüsü içerisinde 10-15 dakika karıştırıldı, uygun viskozite sağlandığında bir bakır tel (yaklaşık 0,40,5 mm çap, 0,1-0,2 mm uzunlukta metalik açıklık ve geri kalan 5-6 cm izole kablodan oluşan) bu karışıma 3-5 defa daldırılarak üzeri kapland1 ve $50-60{ }^{\circ} \mathrm{C}$ 'de 24 saat beklemeye birakıldı. PVC membran kokteylinin hazırlandığı ikinci aşamada; ağırlıça \% 4-8 BUS-TFB, \% 62-66 oNFOE veya DOS, \% 30 PVC içeren karışımın THF çözücüsünde çözülmesiyle hazırlandı. Son aşamada katı kontak yüzeyleri, yukarıda bileşimi verilen PVCmembran kokteyline 4-5 defa daldırılarak kaplandı ve oda şartlarında 12 saat kurumaya bırakıldı. Hazırlanan BUS-seçici sensörlerin potansiyometrik davranışları (doğrusal değişim aralıkları, cevap zamanları, tayin limitleri ve kullanım ömürleri v.b.) IUPAC önerilerine göre incelendi (Buck ve Lindner, 1994). Busulfanın sudaki ve pH'ya bağlı çözünürlüğünün k1sıtlı olması nedeniyle pH çalışma aralığı araştırması yapılamadı. Sensörler ölçümden önce $10^{-3} \mathrm{M}$ derişimindeki standart BUS çözeltilerinde 6 saat şartlandırıldı. Sensörler kullanımda oldukları zaman dilimi içerisinde kuru olarak veya deiyonize su içinde sakland. Potansiyel ölçümleri, sensör ve referans elektrodun 5 mL'lik çözeltiye aynı derinlikte daldırılmasıyla gerçekleştirildi. Her ölçümden önce sensör ve referans elektrot deiyonize su ile yıkandı. Ölçümler çoğunlukla $\quad 10^{-2}-10^{-7} \quad \mathrm{M}$ derişim aralığındaki standart çözeltilerde gerçekleştirildi. Çalışmada kullanılan potansiyometrik ölçüm hücresi şematik olarak aşağıda verilmiştir.

$\mathrm{Cu}$ | kat1-kontak | BUS-seçici membran | test çözeltisi || referans elektrot (Ag/AgCl)

\section{Bulgular ve Tartışma}

\subsection{BUS-TPB Iyon Çiftinin Elementel Analizi}

Sentezlenen iyon çifti içerisinde hangi oranlarda birleşme olduğunun tespiti için $\mathrm{C}, \mathrm{S}$ ve $\mathrm{H}$ elementlerinin elementel analizleri gerçekleştirildi. Elde edilen sonuçlara göre; \% C=63,76 (teorik: 63,61 ), $\% \mathrm{~S}=11,35$ (teorik: 11,32 ) ve $\% \mathrm{H}=6,28$ (teorik: 6,23) olarak belirlenmiştir. Buna göre BUS-TPB iyon çiftinde busulfan ile tetrafenilboratın 1:1 oranında birleştiği sonucuna varılmıştır.

\subsection{Optimum Membran Bileşimi}

İyon seçici elektrotlar için ideal membran bileşiminin belirlenmesi önemli bir parametredir. Membran bileşimini oluşturan türler ve miktarları sensör performansını etkilemektedir. 
Tablo 1. BUS-seçici sensörler için membran bileşimleri ve bazı performans özellikleri

\begin{tabular}{|c|c|c|c|c|c|c|c|}
\hline \multicolumn{5}{|c|}{ Membran Bileşimi (\% Küitlece) } & \multicolumn{3}{|c|}{ Potansiyometrik Davranış } \\
\hline Sensör & BUS-TFB & PVC & o-NFOE & DOS & Eğim $(m V)^{*}$ & $\begin{array}{c}\text { Doğrusal } \\
\text { Çalışma Aralığı } \\
\text { (M) }\end{array}$ & Tayin Limiti (M) \\
\hline BUS-I & 4 & 30 & 66 & - & $35,0 \pm 2,3$ & $1,0 \times 10^{-2}-1,0 \times 10^{-4}$ & $7,1 \times 10^{-5}$ \\
\hline BUS-II & 8 & 30 & 62 & & $20,5 \pm 4,1$ & $1,0 \times 10^{-2}-1,0 \times 10^{-4}$ & $6,3 \times 10^{-5}$ \\
\hline $\begin{array}{l}\text { BUS- } \\
\text { III }\end{array}$ & 4 & 30 & - & 66 & $53,3 \pm 3,4$ & $1,0 \times 10^{-2}-2,5 \times 10^{-5}$ & $1,8 \times 10^{-5}$ \\
\hline $\begin{array}{l}\text { BUS- } \\
\text { IV }\end{array}$ & 8 & 30 & - & 62 & $46,5 \pm 3,2$ & $1,0 \times 10^{-2}-5,0 \times 10^{-5}$ & $4,5 \times 10^{-5}$ \\
\hline
\end{tabular}

* Doğrusal aralığa karşılık gelen eğim değerleri olup N=3 için standart sapmaları ile birlikte verilmiştir.

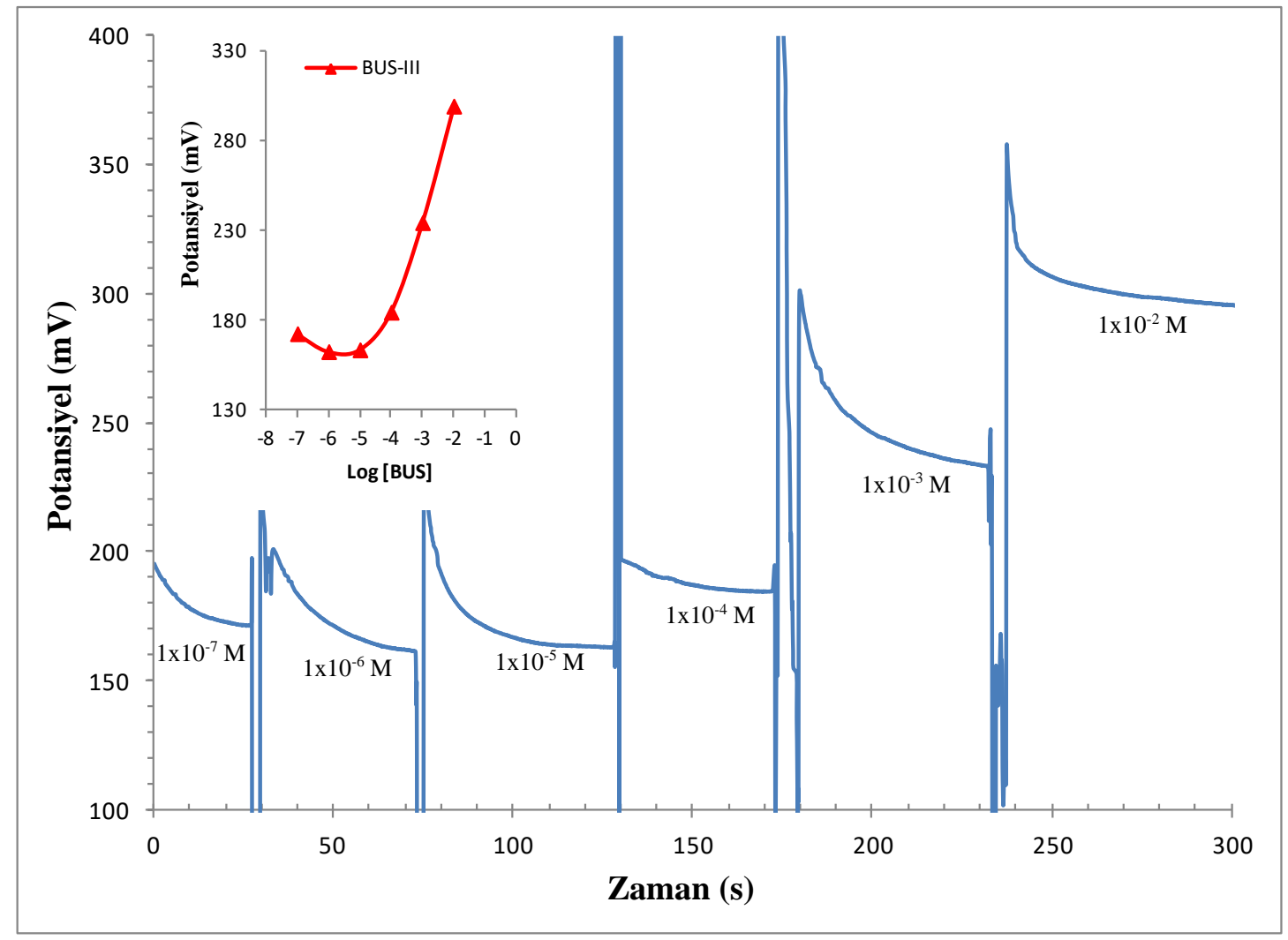

Şekil 2. BUS-seçici sensöre ait potansiyel-zaman ve kalibrasyon grafiğgi

$\mathrm{Bu}$ amaçla farklı membran bileşimlerine sahip çok sayıda sensör hazırlandı ve en iyi performansı sergileyen sensör seçilerek potansiyometrik performans özellikleri test edildi. Hazırlanan sensörler için test edilen membran bileşimleri ve bazı potansiyometrik performans özellikleri (eğim, doğrusal çalışma aralığı, tayin limiti ve cevap zamanı) Tablo 1'de verilmiştir. Tablo 1 incelendiğinde; özellikle eğim ve tayin limiti açısından BUS-3 olarak tanımlanan sensörün diğer sensörlere göre daha iyi performans sergilediği görülmektedir. Dolayısıyla çalışmanın devamında BUS-III adlı sensörün potansiyometrik performans özellikleri daha ayrıntılı olarak incelenmiş ve elde edilen sonuçlar sırasıyla aşağıda özetlenmiştir. Şekil 2'de $10^{-7}-10^{-2} \mathrm{M}$ derişim aralığındaki standart busulfan çözeltilerine sirasıyla daldırılan BUS-seçici sensörün potansiyometrik davranışı ve bu davranışa ait kalibrasyon grafiğgi görülmektedir. Sensörün geniş bir 
derişim aralığında $\left(2,5 \times 10^{-5}-1,0 \times 10^{-2} \quad \mathrm{M}, \quad\right.$ BUS-seçici sensörün potansiyometrik $\left.\mathrm{R}^{2}=0,990\right)$ doğrusal davrandı̆̆ 1 , çok düşük davranışı ve bu davranışa karşılık çizilen BUS derişimlerine $\left(\sim 10^{-6} \mathrm{M}\right)$ cevap kalibrasyon grafiği birlikte görülmektedir. sergilediği ve kısa cevap zamanına $(25 \mathrm{~s})$ Kalibrasyon grafiğinden geliştirilen BUSsahip olduğu görülmektedir. Sensörün tayin seçici sensörün çok sayıda ara çözeltiye karşı sınırı IUPAC'a göre (Buck ve Lindner, 1994) $1,8 \times 10^{-5} \mathrm{M}$ ve her logaritmik artışta derişim birimi için ortalama potansiyel değişimi (eğim) 53,3 $\pm 3,4 \mathrm{mV}$ olarak hesaplanmıştır. Sensörün cevap zamanını belirlemesi amaciyla $10^{-5}-10^{-1} \mathrm{M}$ derişimdeki standart BUS çözeltileri için denge potansiyellerine geçiş süreleri ( $t_{95}$ ) kaydedildi. Elde edilen değerlerin ortalaması alınarak sensörün cevap zamanı hesaplandı.

\subsection{Kalibrasyon Çalışması}

Şekil 3'de $10^{-5}-10^{-2} \mathrm{M}$ derişim aralığındaki BUS ara çözeltilerine sırasıyla daldırılan

\subsection{Tekrarlanabilirlik Çalışması}

Geliştirilen sensörün tekrarlanabilirliğini ortaya koymak amaciyla; BUS-seçici sensör $10^{-2}$ ve $10^{-3} \mathrm{M}$ derişimlerindeki standart BUS çözeltilerine sırasıyla $10 \mathrm{kez}$ daldırılmış ve tekrarlanan potansiyometrik ölçümler alınmıştır (Şekil 4). BUS-seçici sensöre ait tekrarlanabilirlik ölçümleri için potansiyel değerleri, ortalama ve standart sapmaları ile birlikte Tablo 2'de verilmiştir. Sensörün oldukça tekrarlanabilir sonuçlar sergilediği söylenebilir.

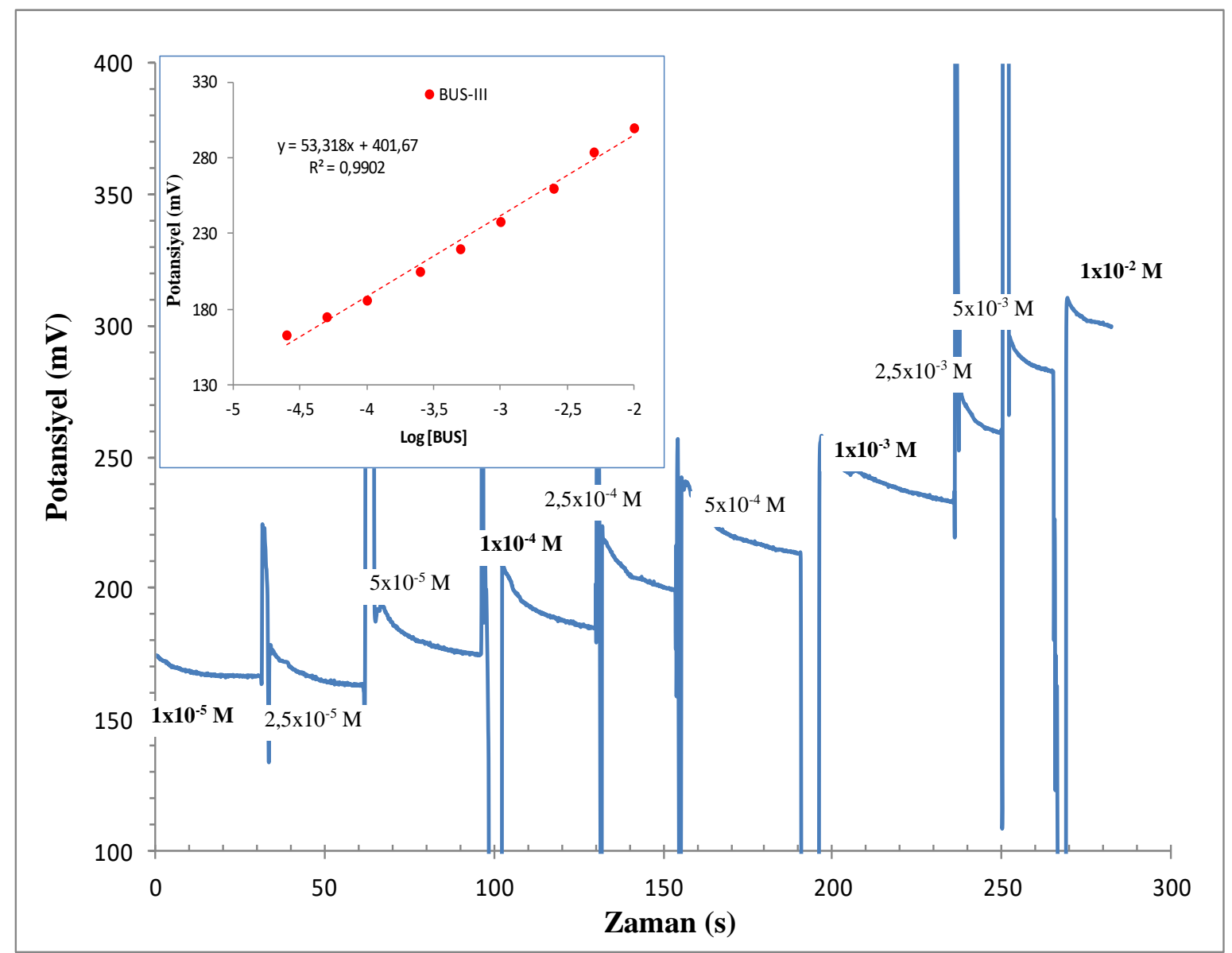

Şekil 3. BUS-seçici sensöre ait potansiyel-zaman ve kalibrasyon grafikleri (ara çözeltiler için) 


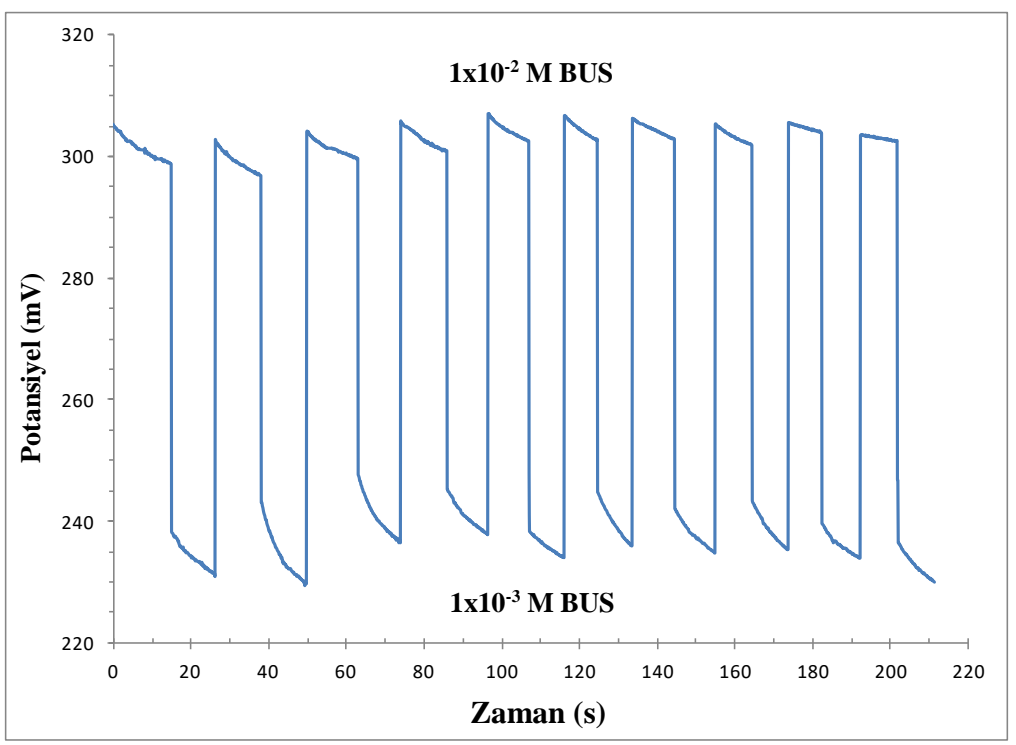

Şekil 4. BUS-seçici sensöre ait tekrarlanabilirlik ölçümleri

Tablo 2. BUS-seçici sensöre ait tekrarlanan ortalama potansiyel değerleri

\begin{tabular}{|c|c|c|c|c|c|c|c|c|c|c|c|}
\hline \multirow{2}{*}{$\begin{array}{l}\text { Derişim } \\
\text { (M) }\end{array}$} & \multicolumn{10}{|c|}{ Tekrarlanan Potansiyometrik Ölçümler (mV) } & \multirow[b]{2}{*}{$(\overline{\mathbf{X}} \pm \mathbf{s})^{*}$} \\
\hline & 1 & 2 & 3 & 4 & 5 & 6 & 7 & 8 & 9 & 10 & \\
\hline $10^{-2}$ & 299,7 & 298,6 & 301,3 & 302,5 & 304,0 & 304,2 & 304,2 & 303,3 & 304,6 & 303,1 & $302,6 \pm 2,1$ \\
\hline $10^{-3}$ & 233,5 & 232,3 & 239,2 & 239,5 & 235,1 & 237,9 & 236,4 & 237,3 & 234,7 & 232,5 & $235,8 \pm 2,6$ \\
\hline
\end{tabular}

*N=10 için ortalama değer olup standart sapması ile birlikte verilmiştir.

\subsection{Sensörün Kullanım Ömrü}

Geliştirilen BUS-seçici sensörün kararlılığını belirlemek amacıyla; yaklaşık 60 gün boyunca belirli periyotlarda tekrar ölçümleri alınmış ve eğim değerleri grafiksel olarak Şekil 5'te verilmiştir. Grafik analiz edildiğinde yaklaşık olarak 6 hafta boyunca eğim değerinde fazla bir değişim olmaksızın sensörün kararlı davrandığı söylenebilir.

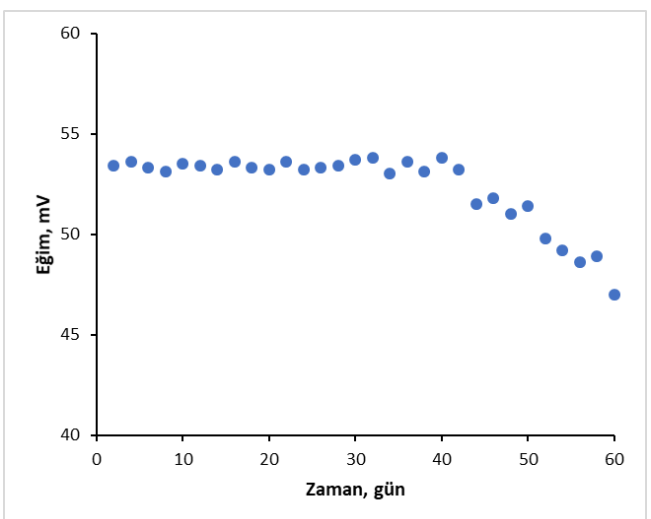

Şekil 5. BUS-seçici sensöre ait kararlılık grafiği

\subsection{Sıcaklık-Performans Çalışması}

Sıcaklık, iyon seçici elektrotlar için incelenmesi gereken diğer önemli bir parametredir. Sicaklık, sensör ve referans elektrot potansiyelini etkileyebilir. Literatürde bazı kimyasal sensörler için sicaklık karakteristikleri sunulmuştur. Elde edilen veriler sıcaklık etkisinin karmaşık olduğunu ve değişken çevresel koşulların sensörleri etkileyebileceğini göstermektedir. Sensörler bazen çalışma teorisini takip etmezler. Ancak ideal bir elektrot için, gerçek eğim sicaklık arttıkça artar (Dybko, 2001 ve Tinneri, 2004). Geliştirilen BUSseçici sensörün optimum çalışabileceği sıcaklık aralığının tespit edilmesi amacıyla; $10^{-2} \mathrm{M}$ standart BUS çözeltisinin $5{ }^{\circ} \mathrm{C}$ 'den 50 ${ }^{\circ} \mathrm{C}$ 'ye kadar belirli aralıklarla sıcaklığ değiştirildi ve her sıcaklık değişimi için potansiyel ölçümü alındı. BUS-seçici 
sensörün sıcaklık değişimine karşı davranışı grafiksel olarak Şekil 6'da görülmektedir. Grafik incelendiğinde; geliştirilen BUS seçici sensörün yaklaşık olarak $15-40{ }^{\circ} \mathrm{C}$ sicaklık aralığında beklendiği gibi az bir değişim ile çalıştığ1 görülmektedir. Yaklaşık $15{ }^{\circ} \mathrm{C}$ 'nin altında ve $40{ }^{\circ} C^{\prime}$ 'nin üzerinde, sensör performansının sicaklık değişiminden oldukça fazla etkilendiği görülmektedir.

Ayrıca $40 \quad{ }^{\circ} \mathrm{C}$ 'nin üzerinde yapılan ölçümlerden sonra sensörün geri dönüşümsüz olarak deforme olduğu tespit edilmiştir.

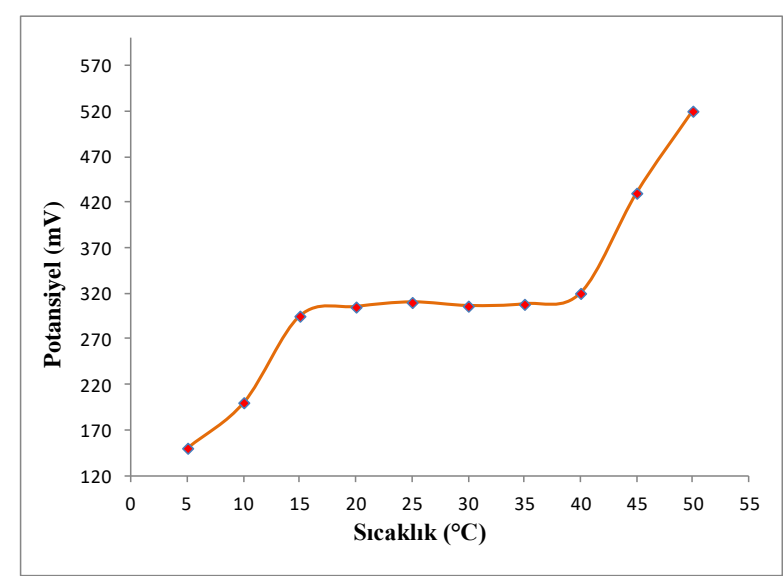

Şekil 6. BUS-seçici sensöre ait sıcaklık davranışı

\subsection{Seçicilik Çalışması}

Geliştirilen BUS-seçici sensörlerin BUS yanında girişimi muhtemel olabilecek yaygın iyonik türlere karşı seçiciliği ayrı çözelti metodu (Buck ve Lindner, 1994) ile aşağıda verilen Nicolsky eşitliği yardımıyla hesaplanmıştır.

$$
\mathrm{K}_{\mathrm{A}, \mathrm{B}}^{\text {pot }}=\frac{a_{\mathrm{A}}}{a_{\mathrm{B}}^{\mathrm{z}_{\mathrm{A}} / \mathrm{Z}_{\mathrm{B}}}}
$$

Hesaplanan seçicilik katsayıları logaritmik olarak Tablo 3'te verilmiştir. Tablo 3 incelendiğinde, sensörün birçok tür yanında busulfana karşı seçici davrandığ 1 söylenebilir. Sensörün potansiyometrik davranışına en fazla $\mathrm{Cu}^{2+}$ iyonunun girişim yaptığ1 görülmektedir. $\mathrm{Pb}^{2+}, \mathrm{Cr}^{3+}$ ve $\mathrm{Fe}^{3+}$ gibi iyonik türlerle temas eden sensörün dengeye gelme zamanının oldukça uzadığı ve bu türlerden olumsuz etkilendiği de ayrıca tespit edilmiştir. Bu durumun ilgili iyonik türlerin membran yüzeyine adsorbsiyon etkilerinin fazla olması nedeniyle oluştuğu

düşünülmektedir.

Tablo 3. BUS-seçici sensöre ait logaritmik seçicilik katsayıları

\begin{tabular}{cccc}
\hline Türler & $\log \mathbf{K}_{\mathbf{A}, \mathbf{B}}$ & Türler & $\log \mathbf{K}_{\mathbf{A}, \mathbf{B}}$ \\
\hline $\mathrm{Cu}^{2+}$ & $-1,03$ & $\mathrm{~Pb}^{2+}$ & $-1,68$ \\
$\mathrm{Co}^{2+}$ & $-1,23$ & $\mathrm{Ni}^{2+}$ & $-1,84$ \\
$\mathrm{Fe}^{3+}$ & $-1,25$ & $\mathrm{~K}^{+}$ & $-2,27$ \\
$\mathrm{NH}^{+}$ & $-1,33$ & $\mathrm{Mg}^{2+}$ & $-2,32$ \\
$\mathrm{Na}^{+}$ & $-1,42$ & $\mathrm{Zn}^{2+}$ & $-2,61$ \\
$\mathrm{Cd}^{2+}$ & $-1,58$ & $\mathrm{Li}^{+}$ & $-2,65$ \\
$\mathrm{Cr}^{3+}$ & $-1,64$ & $\mathrm{Ca}^{2+}$ & $-2,56$ \\
\hline
\end{tabular}

\subsection{Titrasyon Uygulamast}

Geliştirilen BUS-seçici sensörün indikatör elektrot olarak sergilemiş olduğu potansiyometrik davranışının incelenmesi amaciyla; $10 \mathrm{~mL} \quad 10^{-3} \mathrm{M}$ standart BUS çözeltisinin $10^{-3} \mathrm{M}$ NaTFB çözeltisi ile titrasyonunda potansiyometrik ölçümler alınmıştır. Şekil 7'de titrasyon sonucu elde edilen grafik ve Tablo 4'te hesaplanan dönüm noktası değerleri görülmektedir. Yaklaşık \% 5'lik bağıl hata ile dönüm noktası başarıyla tespit edilmiştir.

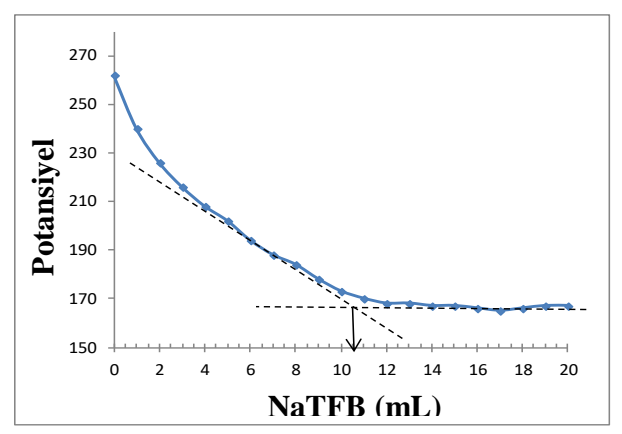

Şekil 7. BUS-seçici sensörün indikatör elektrot olarak davranışı (titrasyon eğrisi)

Tablo 4. BUS ile NaTFB titrasyonu için belirlenen dönüm noktası değerleri

\begin{tabular}{lccl}
\hline & $\begin{array}{c}\text { Dönüm noktası, } \\
\mathrm{mL}\end{array}$ & $\begin{array}{c}\text { BUS miktarı, } \\
\mathrm{mg}\end{array}$ & $\begin{array}{l}E_{r} \\
(\%)^{* *}\end{array}$ \\
\cline { 1 - 3 } Deneysel* $^{*}$ & $10,50 \pm 0,50$ & $2,59 \pm 0,12$ & \\
\cline { 1 - 3 } Teorik & 10,00 & 2,46 & \\
\hline
\end{tabular}

*N=3 için ortalama değer standart sapması ile birlikte verilmiştir.

** Deneysel ve teorik veriler için yüzde bağıl hata değeridir. 
Tablo 5. Potansiyometri ve UV yöntemleri ile ticari ilaç numunesinde belirlenen BUS miktarları

\begin{tabular}{|c|c|c|c|c|c|}
\hline \multirow{2}{*}{ Numune } & \multirow{2}{*}{ Etiket değeri (mg) } & \multicolumn{2}{|c|}{ Tablet başına BUS miktarları (mg) ${ }^{\text {a }}$} & \multirow{2}{*}{$E_{r}(\%)^{b}$} & \multirow{2}{*}{$t_{\text {deneysel }} \mathrm{c}$} \\
\hline & & Potansiyometri & $\mathbf{U V}$ & & \\
\hline Myleran ${ }^{\circledR}$ & 2,00 & $1,94 \pm 0,23$ & $2,09 \pm 0,09$ & $-2,85$ & 0,47 \\
\hline
\end{tabular}

\subsection{Farmasötik Numune Analizi}

Geliştirilen sensörün önemli diğer bir analitik uygulaması olarak gerçek numune analizleri gerçekleştirildi. Bu amaçla DNA-etkileşimli alkilleyici ajanlar sınıfina giren, kanser tedavisinde kullanılan ve ticari adı Myleran ${ }^{\circledR}$ (2 mg) olan ilacın içerdiği busulfan miktarı belirlenmeye çalışıldı. Yerel bir eczaneden satın alınan ilgili ilacın potansiyometrik ve spektroskopik analizleri gerçekleştirildi. $\mathrm{Bu}$ amaçla ilk olarak 2 adet ilaç tableti havanda ezilerek toz haline getirildi ve $0,1875 \mathrm{~g}$ toz ilaç $100 \mathrm{~mL} \mathrm{pH}: 7,05$ fosfat tamponunda çözüldü. Elde edilen çözelti 0,45 mikronluk filtrelerden süzüldü ve sonrasinda süzüntünün potansiyeli geliştirilen BUSseçici sensör ile ölçüldü. Standart ekleme yöntemi kullanılarak hesaplamalar yapıldı. Spektroskopik analiz için $100 \mathrm{mg}$ toz ilaç 10 $\mathrm{mL}$ asetonitrilde çözüldü, çözelti 0,45 mikronluk filtrelerden süzüldü ve sonrasında $281 \mathrm{~nm}$ dalga boyunda UV-Vis ölçümleri alındı ve sonuçlar hesaplandı. Her iki metotla elde edilen sonuçlar için istatistiksel hesaplamalar yapıldı (Tablo 6). Elde edilen sonuçlara istatistiksel çift taraflı t-testi uyguland1 ve "Yok Hipotezi" kabul edildi (Skoog vd., 2004).

$$
t=\left(\mu-\bar{x}_{d}\right) \cdot \sqrt{n} / S_{d}
$$

(Eşitlik 2)

Yukarıdaki eşitlikten hesaplanan $\mathrm{t}$ değeri $(0,47) \% 95$ güven aralığında $(\mathrm{P}=0,05)$ serbestlik derecesi 4 için tablodan bulunan kritik $\mathrm{t}$ değeri $(2,78)$ ile kıyasland. $t_{\text {kritik }}>t_{\text {deneysel }}$ olduğundan her iki yöntem (potansiyometri ve UV) ile elde edilen ortalama busulfan değerlerinin birbirinden önemli derecede farklı olmadığı sonucuna varildi.

\section{Sonuç ve Öneriler}

Çalışma kapsamında, iyon çifti yöntemi ile sentezlenen bileşik iyonofor olarak kullanildı. Sentezlenen bu iyonofor ile busulfan seçici yapı oluşturuldu. BUS-seçici PVC membran potansiyometrik mikrosensörler hazırlandı. BUS-seçici PVC membran sensör potansiyometrik titrasyonlarda indikatör elektrot olarak başarı ile kullanıld1. Geliştirilen BUS-seçici sensör ile farmasötik numunede bulunan busulfanın ekonomik, hızlı, doğru, seçici ve tekrarlanabilir tayini başarı ile gerçekleştirildi. Geliştirilen sensör için düşük ölü hacme sahip akış hücreleri hazırlamaya uygundur. Dolayısıyla kromatografi gibi hareketli ortamlarda dedektör olarak rahatlıkla uygulanma imkanına sahiptir.

\section{Teșekkürr}

$\mathrm{Bu}$ çalışmanın potansiyel ölçümlerinde kullanılan çok kanallı potansiyometrenin dizayn edilmesinde FEN-BAP-A-160512-36 numaralı proje ile destek olan Giresun Üniversitesi BAP Koordinatörlüğüne ve ayrıca Elementel Analiz ve UV ölçümleri için Merkezi Araştırma Laboratuvarı Uygulama ve Araştırma Merkezine (GRÜMLAB) teşekkürlerimizi sunarız. 


\section{Kaynaklar}

Abdel-Rehim, M., Hassan, Z., Blomberg, L., Hassan, M. 2003. "On-line Derivatization Utilizing Solid-phase Microextraction (SPME) for Determination of Busulphan in Plasma using Gas Chromatography-mass Spectrometry (GC-MS)", Therapeutic Drug Monitoring, 25(3), 400-406.

Buck, R. P., Lindner, E. 1994. "IUPAC Analytical Chemistry Division, Commission on Electroanalytical Chemistry,. Recomendations for nomen-clature of Ion-selective Electrodes", Pure Appl. Chem., 66, 2527-2536.

Burns, R. B., Heggie, J. R., Embree, L. 1995. "A gas-chromatographic assay method for busulfan with sensitivity for test dose therapeutic monitoring", Journal of Pharmaceutical and Biomedical Analysis, 13, 1073-1078.

Çoldur, H., Boz, H., Önder, A. 2015. "Bütünüyle Katı Hal PVC Membran İzoniazid-Seçici Potansiyometrik Sensör", Erzincan Üniversitesi Fen Bilimleri Enstitüsü Dergisi, 9(1), 2939.

Dybko, A. 2001. "Errors in Chemical Sensor Measurements", Sensors-Basel, 1, 2937.

Ensafi, A. A., Allafchian, A. R. 2011. "Potentiometric Sensor for the Determination of Dibucaine in Pharmaceutical Preparations and Electrochemical Study of the Drug with BSA". Bull. Korean Chem. Soc., $32(8), 2722$.

Eren E., Ata A., Arıcan A. 2012. "Kanser Tedavisinde Kullanılan İlaçlar ve Nefrotoksisite", DEÜ Tip Fakültesi Dergisi, 26(3), 229-235.
Gezmen-Karadağ, M., Türközü, D., Topağaç Kapucu, D. 2013. "Bitkiler ve İlaç Etkileşimleri”, Göztepe Tip Dergisi, 28(4), 164-170.

Isildak, I., Yolcu, M., Isildak, O., Demirel, N., Topal, G., Hosgoren, H. 2004. "AllSolid-State PVC Membrane $\mathrm{Ag}^{+}$ Selective Electrodes based on diaza-18Crown-6 Compounds", Microchim Acta, 144(1-3), 177-181.

Jenke A., Renner U., Schuler U. S., Wauer S., Leopold T., Schleyer E., Ehninger G. 2004. "Improved Assay for Determination of Busulfan by Liquid Chromatography using Postcolumn Photolysis", Journal of Chromatography B, 805, 147-153.

Kotinkaduwe, R. P., Kitscha, R. A. 1999. "The Determination of Methanesulphonic Acid Content of Busulfan Drug Substance and Busulfan (Myleran ${ }^{\circledR}$ ) Tablets by Ion Chromatography", Journal of Pharmaceutical and Biomedical Analysis, 21, 105-113.

Ma'mun, A., Abd El-Rahman, M. K., Abd, El-Kawy, M. 2018. "Real-time potentiometric sensor; An innovative tool for monitoring Hydrolysis of chemo/bio-degradable Drugs in pharmaceutical sciences", Journal of Pharmaceutical and Biomedical Analysis, 154, 166-173.

Mürdter, T. E., Coller, J., Claviez, A., Schönberger, F., Hofmann, U., Dreger, P., Schwab, M. 2001. "Sensitive and Rapid Quantification of Busulfan in Small Plasma Volumes by Liquid Chromatography-Electrospray Mass Spectrometry", Clinical Chemistry, 47, 1437-1442.

Nussbaumer, S., Bonnabrya, P., Veuthey, J. L., Fleury-Souverain, S., 2011. 
"Analysis of Anticancer Drugs: A Tinneri U. 2004. "Electrodes in review", Talanta, 85, 2265-2289. Potentiometry", Metrohm Monographs,

Peris J. E., Latorre J. A., Castel V., p2. Verdeguer A., Esteve S., TorresMolina F. 1999. "Determination of Busulfan in Human Plasma using High-Performance Liquid Chromatography with pre-column Derivatization and Fluorescence Detection", Journal of Chromatography $B, 730,33-40$.

Quernin, M. H., Poonkuzhali, B., Medard, Y., Dennison, D., Srivastava, A., Krishnamoorthy, R., Chandy, M., Jacqz-Aigrain, E. 1999. "HighPerformance Liquid Chromatographic Method for Quantification of Busulfan in Plasma after Derivatization by Tetrafluorothiophenol", Journal of Chromatography B, 721(1), 147-152.

Shawish, H. M. A., Saadeh, S. M., Tamos, H., Abed-Almonem, K. I., Khalilie, O. A. 2015. "A new potentiometric sensor for the determination of ketamine hydrochloride in ampoules and urine". Analytical Methods. 7, 301-308.

Singhal B. 2011. "Drug Analysis: A Perspective of Potentiometric Sensors". World Journal of Chemistry, 6, (2), 5974.

Skoog, D. A., West, D. M., Holler, F. J., Crouch, S. R. 2004. "Fundamentals of Analytical Chemistry, Analitik Kimya Temel İlkeler, 8. Baskı", (Çeviri Editörleri: Esma Kılıç, Hamza Y1lmaz), Bilim Yayıncılık, Ankara, 620-621.

Tang, X. C., Wang, P. Y., Buchter, G. 2018. "Ion-Selective Electrodes for Detection of Lead (II) in Drinking Water: A Mini-Review", Environments, 5, 95, 114. 